\title{
PERAMALAN JUMLAH MAHASISWA MENGGUNAKAN MOVING AVERAGE
}

\author{
Hari Prapcoyo \\ Sistem Informasi, Fakultas Teknik Industri \\ Universitas Pembangunan Nasional "Veteran" Yogyakarta \\ e-mail : hari.prapcoyo@upnyk.ac.id
}

\begin{abstract}
The Process of using resources in higher education is influenced by the up and down of the number students. The purpose of this study is to predict the number of students who study in the department of informatics engineering UPN Veteran Yogyakarta for the next periods. This research, data is taken from forlap dikti for Informatics Engineering fom 2009 until 2016 at UPN Veteran Yogyakarta. The method that used to forecast the number of students is a Moving Average method consisting of: Single Moving Average (SMA), Weighted Moving Average (WMA) and Exponential Moving Average (EMA). This study will use the forecasting accuracy namely Mean Square Error (MSE), Mean Absolute Error (MAE) and Mean Absolute Percentage Error (MAPE) to select the best model to be used for forecasting. The best model that used for forecasting is Weighted Moving Average (WMA) with weighted 1/3 and average length (n) used for 2. The smallest value for MSE of 5807.96; the smallest MAE value of 55.89 and the smallest value for MAPE of 5.24\%. Forecasting of the number of students for four semesters in the future after the even semester of 2016 are respectively: 902; 901,33; 901,56 and 901,48.
\end{abstract}

\section{Keywords : Forecasting, UPN Veteran Yogyakarta, Single moving average(SMA)}

\begin{abstract}
Abstrak
Proses penggunaan sumber daya perguruan tinggi setiap tahun dipengaruhi oleh naik turunnya jumlah mahasiswa. Tujuan dari penelitian ini adalah untuk memprediksi jumlah mahasiswa yang kuliah di jurusan teknik informatika UPN Veteran Yogyakarta untuk periode yang akan datang. Data penelitian ini diambil dari forlap dikti untuk Teknik Informatika dari tahun 2009 sampai 2016 UPN Veteran Yogyakarta. Metode yang digunakan untuk melakukan peramalan jumlah mahasiswa adalah metode Moving Average yang tediri dari : Single Moving Average (SMA), Weighted Moving Average (WMA) dan Exponential Moving Average (EMA). Penelitian ini akan menggunkan akurasi peramalan Mean Square Error (MSE), Mean Absolute Error (MAE) dan Mean Absolute Percentage Error (MAPE) untuk memilih model terbaik yang akan digunakan untuk peramalan. Model terbaik yang digunakan untuk peramalan yaitu Weighted Moving Average (WMA) dengan pembobot $1 / 3$ dan panjang rata-rata (n) yang dipakai sebesar 2 . Nilai terkecil untuk MSE sebesar 5807,96; nilai terkecil MAE sebesar 55,89 dan nilai terkecil untuk MAPE sebesar 5,24 \%. Peramalan untuk jumlah mahasiswa empat semester kedepan setelah semester genap 2016 masing-masing adalah : 902; 901,33; 901,56 dan 901,48.
\end{abstract}

Kata Kunci : Peramalan, UPN Veteran Yogyakarta, Single Moving Average(SMA).

\section{PENDAHULUAN}

Dalam penggunaan sumber daya perguruan tinggi baik dalam bentuk infrastruktur, sumber daya manusia, perencanaan proses belajar mengajar sebaiknya menggunakan perhitungan yang akurat. Perhitungan peramalan dalam banyak hal dijadikan acuan sebagai langkah menuju sesuatu yang ideal / sesuai standard sehingga output mempunyai kualitas yang bagus dengan melihat kondisi yang ada saat ini. Kemampuan melakukan peramalan ini juga dipengaruhi oleh budaya organisasi ataupun berdirinya sebuah Perguruan Tinggi tersebut. UPN 
Veteran Yogyakarta berdiri dari tahun 1959, untuk program studi teknik informatika berdiri pada tahun 1995. Prediksi jumlah mahasiswa ini mempunyai keterkaitan dengan proses belajar mengajar, kelas yang siap digunakan, laboratorium pendukung kegiatan praktikum mahasiswa dan hal yang paling pentng adalah rasio ideal antara dosen dan mahasiswa. Jumlah mahasiswa memegang peranan penting untuk penyediaan fasilatas lain. Untuk melakukan prediksi jumlah mahasiswa yang kuliah tiap semester tersebut, tersedia data yang bersumber pada forlap PD Dikti persemester untuk tahun 2009 - 2016.

Dengan jumlah data yang tersedia, bagaimana memperoleh informasi jumlah mahasiswa persemester yang akan datang tersebut merupakan permasalah penting yang diangkat dalam penelitian ini. Untuk menjawab prediksi jumlah mahasiswa yang kuliah di setiap semester tahun yang akan datang akan dilakukan peramalan jumlah mahasiswa yang kuliah tiap semesternya di program studi teknik informatika dengan menggunakan metode Moving Average (MA). Peramalan jumlah mahasiswa persemester yang akan datang tersebut akan sangan mempermudah malakukan perencanaan yang lain. Pada dasarnya metode peramalan ini merupakan perhitungan peramalan yang sederhana dengan menggunakan sekumpulan data historis dengan mencari rata rata bergerak untuk membuat perkirakan kondisi pada masa yang akan datang. Meskipun demikian dalam banyak peramalan tetap perlu mempertimbangkan kondisi data yang akan digunakan / dianalisis.

\section{TINJAUAN PUSTAKA}

Dalam beberapa tahun terakhir ini metode moving average juga masih banyak digunakan karena kesederhanaannya dan sesuai dengna kondisi data yang akan diramalkan. Metode ini juga dilakukan modifikasi dengan dikombinasikan dengan metode yang lain seperti autoregressive integrated moving average (ARIMA)(Makridakis, Wheelwright dan McGee, 1995). Selanjutnya metode moving average ini masih bisa dan layak digunakan untuk membuat peramalan yang sederhana dan praktis serta digunakan beberapa peneliti untuk meramalkan data yang akan datang. Penelitian-penelitian itu diantaranya, Penelitian (Lauren, 2014) tentang prediksi saham yang dikaitkan dengan klasifikasi berita yang bersifat positif, negatif maupun netral yang mempengaruhi sentiment pasar dengan menggunakan single moving average; Pendekatan moving average method yang dilakukan oleh (Hansun, 2013) menggabungkan rentet waktu (time series) untuk memprediksi indek saham gabungan (IHSG); Peramalan jumlah mahasiswa STIMATA oleh (Asad, Wibowo and Sophia, 2017) yang dikombinasikan dengan autoregressive integrated moving average dengan runtut waktu. Secara definisi moving average adalah perhitungan untuk menganalisis titik data dengan menciptakan serangkaian nilai rata-rata dari himp unan per bagian yang berbeda dari kumpulan data seluruhnya. Jenis moving average yang lazim digunakan yaitu single, exponential, smoothed dan linear weighted moving averages. Dalam penelitian ini hanya akan membahas dengan perhitungan single, weighted dan exponential.

\subsection{Single Moving Average (SMA)}

Menurut Makridakis, Wheelwright dan McGee (1995) Single Moving Average (SMA) atau Ratarata bergerak Tunggal adalah nilai rata-rata yang tidak tertimbang dari $n$ data sebelumnya atau dengan kata lain Sebuah teknik yang merata-ratakan sebuah angka dari nilai aktual terbaru, diperbaharui sebagai nilai-nilai baru yang tersedia. Rumus yang digunakan adalah sbb :

$$
S M A=M_{t}=M_{t+1}=\frac{Y_{t}+Y_{t-1}+Y_{t-2}+\cdots Y_{t-n-1}}{n}
$$


dimana :

Mt $\quad=$ Moving average untuk periode $\mathrm{t}$

$\mathrm{Ft}+1 \quad=$ Ramalan untuk periode $\mathrm{t}+1$

$\mathrm{Yt} \quad=$ Nilai riil periode ke $\mathrm{t}$

$\mathrm{n} \quad=$ Jumlah batas dalam moving average

Untuk memilih panjang rata-rata (n) yang digunakan akan dihitung nilai Akaike Information Criterion (AIC) dan nilai Bayesian Information Criterion (BIC). Nilai AIC dihitung sebagai :

$$
A I C=2 k-2 \ln (L)
$$

dimana, $\mathrm{k}=$ jumlah parameter yang di estimasi

$\mathrm{L}=$ nilai maximun fungsi likelihood

$$
B I C=\ln (n) k-2 \ln (L)
$$

dimana, $\mathrm{k}=$ jumlah parameter yang di estimasi

$\mathrm{L}=$ nilai maximun fungsi likelihood

$\mathrm{n}=$ ukuran sampel

\subsection{Weighted Moving Averages(WMA)}

Rata-rata bergerak tertimbang atau rata-rata bergerak terboboti adalah suatu model peramalan yang dirancang untuk menambah bobot pada data terbaru yang lebih berat dari pada data masa lalu. Jumlah bobot pada model ini sebesar $100 \%$ pada data yang digunakan untuk model peramalan. Pada model SMA bobot dari semua waktu (t) adalah sama, sedang pada model ini data terbaru bobotnya lebih besar dari data yang lalu. Model WMA ini dapat ditulis sebagai (Hansun dan Subanar, 2017) :

$$
W M A_{M}=\frac{n p_{M}+(n-1) n p_{M-1}+2 p_{(M-n+2)}+p_{(M-n+1)}}{n+(n-1)+\cdots+2+1}
$$

dimana,

$\mathrm{n} \quad=$ periode atau time interlude

$p_{m} \quad=$ nilai riil periode ke $\mathrm{m}$

$W M A_{M}=$ nilai ramalan model WMA

\subsection{Exponential Moving Average (EMA)}

Model ini merupakan pengembangan model rata-rata bergerak terboboti (WMA) kearah model exponensial. Bobot yang diberikan sedikit berbeda dengan model WMA, pada model EMA ini data terbaru diboboti lebih besar dari data yang telah lalu dan bobot terlama mendekati nol yang membentuk grafik secara exponensial. Model EMA ini menurut Nist (2018) dapat ditulis sebagai :

$$
S_{1}=Y_{1}, \quad \text { for } t>1, S_{t+1}=\alpha \cdot Y_{t}+(1-\alpha) \cdot S_{t}
$$

dimana,

Yt $\quad=$ Nilai riil periode ke $t$

St $\quad=$ Nilai smooting exponensial EMA periode ke $\mathrm{t}$ 
$\alpha \quad=$ konstata smooting antara 0 sampai dengan 1

$$
\alpha=\frac{2}{(m+1)}
$$

\subsection{Akurasi Peramalan}

Untuk mengetahui akurasi peramalan dilakukan dengan menghitung kesalahan peramalan diantaranya yang digunakan adalah mean square error (MSE), mean absolute error (MAE) dan mean absolute percentage error (MAPE). Perhitungan dari nilai akurasi kesalahan tersebut adalah sebagai berikut (Box et al., 1994)

$$
\begin{gathered}
M S E=\frac{\sum(\text { error })^{2}}{n} \\
M A E=\frac{\sum \mid \text { error } \mid}{n} \\
M A P E=\frac{\sum \mid \text { error } \mid \text { /actual } * 100}{n}
\end{gathered}
$$

Nilai akurasi yang kecil menunjukkan bahwa model lebih akurat hasil peramalannya.

\section{METODE PENELITIAN}

\subsection{Data Penelitian}

Data yang digunakan diambil dari forlap PD Dikti dari semester ganjil 2009 sampai semester genap 2016, dilengkapi data jumlah dosen per tahun. Data rentet waktu ini terdiri dari 16 baris dengan rincian jumlah mahasiswa per semester. Pengolahan data awal dilakukan dengan menganalisis data yang ada. Aspek penting dalam peramalan data adalah dengan mempertimbangkan karakteristik tipe pola data sehingga diharapkan dapat menemukan metode perhitungan yang cocok. Pemilihan metode yang cocok atau sesuai dengan karakteristik data akan mempengaruhi interpretasi terhadap hasil pengujian data yang dijadikan obyek peneltian.

Data hasil penelitian disajikan dalam Tabel 1. dan secara grafik ditampilkan dalam Gambar 1. berikut ini

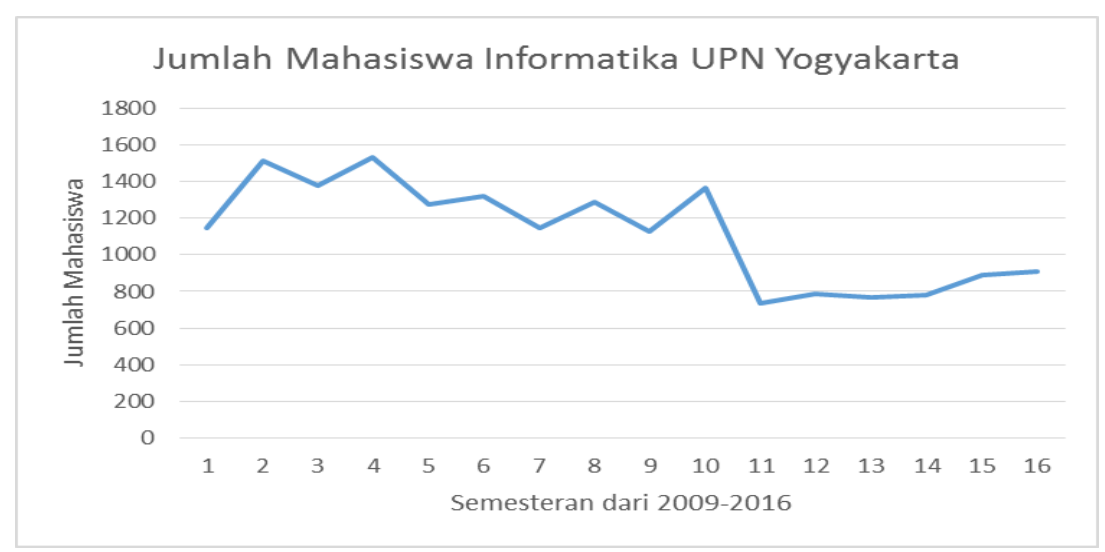

Gambar 1. Plot Jumlah Mahasiswa UPN Yogyakarta semesteran tahun 2009-2016 
Tabel 1. Data Mahasiswa

\begin{tabular}{|c|c|c|c|}
\hline No & Semester & $\begin{array}{c}\text { Jumlah } \\
\text { Mahasiswa }\end{array}$ & $\begin{array}{c}\text { Jml } \\
\text { Dosen }\end{array}$ \\
\hline \hline 1 & Genap 2009 & 1447 & 17 \\
\hline 2 & Ganjil 2009 & 1511 & 17 \\
\hline 3 & Genap 2010 & 1375 & 17 \\
\hline 4 & Ganjil 2010 & 1534 & 17 \\
\hline 5 & Genap 2011 & 1275 & 17 \\
\hline 6 & Ganjil 2011 & 1321 & 17 \\
\hline 7 & Genap 2012 & 1144 & 19 \\
\hline 8 & Ganjil 2012 & 1291 & 19 \\
\hline 9 & Genap 2013 & 1130 & 19 \\
\hline 10 & Ganjil 2013 & 1362 & 19 \\
\hline 11 & Genap 2014 & 737 & 19 \\
\hline 12 & Ganjil 2014 & 785 & 19 \\
\hline 13 & Genap 2015 & 765 & 19 \\
\hline 14 & Ganjil 2015 & 778 & 19 \\
\hline 15 & Genap 2016 & 888 & 19 \\
\hline 16 & Ganjil 2016 & 906 & 19 \\
\hline
\end{tabular}

\subsection{Analisis Data}

Analisis data dilakukan dengan bantuan software $R$ package. Data jumlah mahasiswa dilakukan plotting untuk mendapatkan gambaran pola datanya seperti pada gambar 1. Terlihat bahwa data tidak mengalami trend yang cukup berarti sehingga dilakukan analisis dengan model single moving average, weighted moving average dan exponensial moving average dapat dilakukan.

\subsubsection{Metode Single Moving Average (SMA)}

Metode ini mempunyai karakteristik khusus sebagai berikut :

Untuk menentukan ramalan pada periode yang akan data memerlukan data riwayat selama jangka waktu tertentu.

1. Semakin panjang data riwayat untuk moving average, akan semakin terlihat data peramalan makin halus.

2. Panjang rata-rata bergerak yang digunakan adalah $2(n=2)$, hal ini diambil karena datanya adalah semesteran (dalam satu tahun dua kali semester) dan ini merupakan bentuk siklis pertahun. Nilai $n=2$ ini nantinya akan dirubah menjadi 3, 4, 5 dan 6 . Untuk memilih mana nilai $n$ yang dipakai akan diambil dengan melihat nilai Information criterion (AIC dan BIC) dan nilai akurasi peramalan (MSE, MAE dan MAPE) yang paling kecil.

\subsubsection{Metode Weighted Moving Average (WMA)}

Model weighted moving average (WMA) ini hampir mirip dengan model SMA pada 3.2.1 diatas. Kalau model SMA bobotnya adalah seragam (sama) untuk setiap data rutut waktu (t), sedangkan pada model WMA ini bobotnya berbeda untuk setiap data runtut waktunya. Data terbaru mempunyai bobot yang lebih besar dari data yang lalu. Bobot yang dipakai jika dijumlah harus sebesar $100 \%$. Model rata-rata bergerak terboboti ini menggunakan panjang rata-rata bergerak (n) dari hasil model SMA diatas dengan pembobot yang diberikan menyesuaikan dengan panjang $n$ yang terbaik. Misal untuk $n=5$, pembobot yang diberikan mungkin $5 / 15$, $4 / 15,3 / 15,2 / 15$ dan $1 / 15$. Pembobot yang dipakai akan dipilih dengan melihat nilai akurasi peramalan (MSE, MAE dan MAPE) yang paling kecil.

\subsubsection{Metode Exponential Moving Average (EMA)}

Metode Exponential Moving Average (EMA) bisa dibilang metode motode WMA kusus dengan pembobot yang nilainya bila diplot akan membentuk grafik exponensial. Analisis pada model ini akan menggunakan panjang $n$ sama dengan panjang $n$ pada model SMA dan WMA. Nilai 
pembobot exponensialnya akan dihitung sebesar $1 /(m+1)$, dimana $m$ adalah waktu untuk model WMA atau (t) untuk model SMA. Selanjutnya akan dihitung nilai akurasi peramalan (MSE, MAE dan MAPE).

Dari ketiga model yang dianalisis akan dibandingkan nilai akurasi peramalannya, dimana nilai yang oaling kecil akan digunakan model tersebut untuk memprediksi jumlah mahasiswa yang akan datang mengikuti kuliah di jurusan informatika UPN Yogyakarta.

\section{HASIL DAN PEMBAHASAN}

Berikut ini hasil analisis data untuk model Single Moving Average (SMA), Weighted Moving Average (WMA) dan Exponential Moving Average (EMA). Model yang akan digunakan untuk meramalkan jumlah mahasiswa adalah model yang paling akurat diantara tiga model diatas. Pemilihan model terbaik berdasarakan akurasi peramalan. Berikut hasil analisis data dari ketiga model dan sekaligus perbandingan akurasinya.

\subsection{Model Single Moving Average (SMA)}

Analisis data untuk model ini dengan mengambil $n$ sebesar 2, 3,4,5 dan 6 . Untuk menentukan $n$ yang mau dipakai dibandingkan nilai $A I C$ dan $B I C$ dari $n$ untuk 2-6. Berikut hasil running program yang ditampilkan dalam Tabel 2.

Tampak bahwa hasil nilai terkecil untuk AIC dan BIC ada pada $n=2$, ini berati rata-rata bergerak atau single moving average yang dipakai pada order $n=2$ (panjang rata-ratanya 2 ).

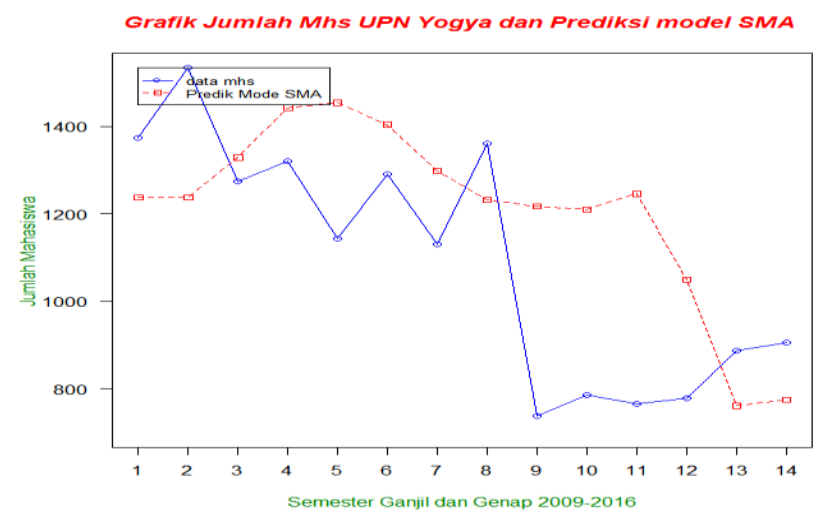

Gambar 2. Plot Nilai aktual dan nilai ramalan model SMA

Tabel 2. Nilai $A I C$ dan $B I C$ untuk n 2-6 pada model Single Moving Average (SMA)

\begin{tabular}{|c|c|c|}
\hline $\mathrm{n}$ & $\begin{array}{c}\text { Nilai Akaike Information } \\
\text { Criterion }(\text { AlC })\end{array}$ & $\begin{array}{c}\text { Nilai Bayesian Information } \\
\text { Criterion }(B / C)\end{array}$ \\
\hline 2 & 191.0244 & 192.3026 \\
\hline 3 & 195.3215 & 196.5997 \\
\hline 4 & 194.7940 & 196.0721 \\
\hline 5 & 196.8424 & 198.1205 \\
\hline 6 & 196.6804 & 197.9585 \\
\hline
\end{tabular}




\subsection{Model Weighted Moving Average (WMA)}

Model WMA ini merupakan pengembangan model SMA dengan pembobot yang diberikan berbeda. Panjang $\mathrm{n}$ (panjang giliran rata-rata) yang diambil mengikuti panjang terbaik dari model SMA. Dengan $n=2$ dan pembobot yang diberikan $2 / 3$ dan $1 / 3$. Hasil peramalan dari model ini ditampilkan dalam bentuk gambar dibawah ini, Gambar 2.

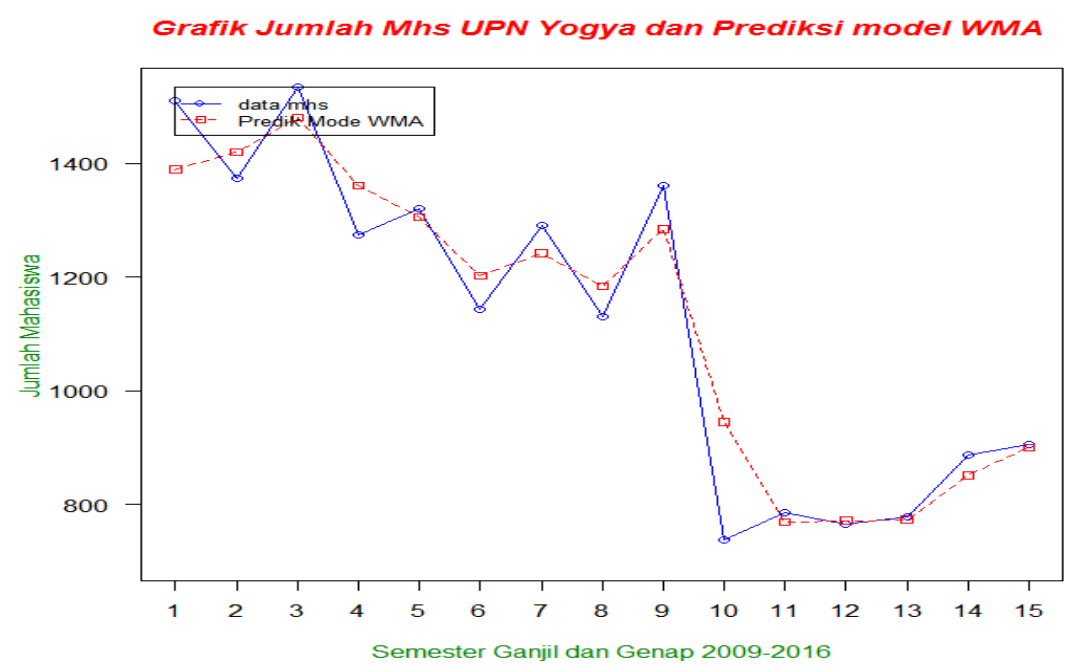

Gambar 3. Plot Nilai aktual dan nilai ramalan model WMA

Prediksi jumlah mahasiswa dengan model WMA ini terlihat secara grafis lebih mengikuti pola jumlah mahasiswa sesungguhnya. Lebih terlihat naik turunnya dengan lebih baik dari rata-rata bergerak saja.

\subsection{Model Exponential Moving Average (EMA)}

Pada model ini merupakan pengembangan model Single Moving Average dengan pembobot kusus yang membentuk grafik exponensial. Pada analisis data model ini pembobot exponensial sebesar 1/3. Berikut hasil analisis secara grafik terlihat pata Gambar 4 dibawah ini.

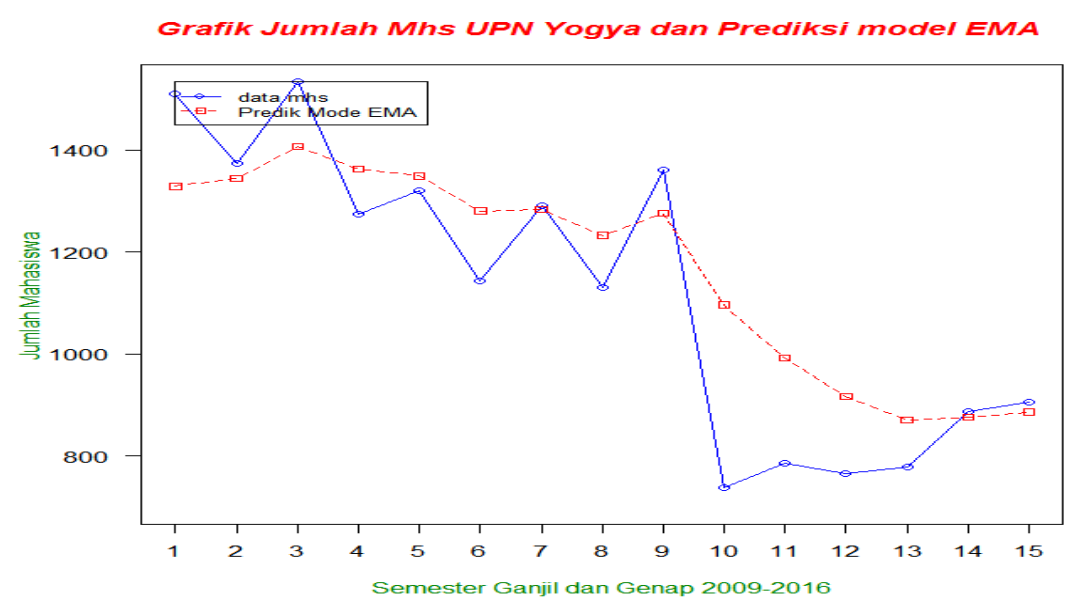

Gambar 4. Plot Nilai aktual dan nilai ramalan model EMA 
Prediksi jumlah mahasiswa dengan model EMA ini terlihat secara grafis lebih mengikuti pola jumlah mahasiswa sesungguhnya sebelum periode ke sembilan, tetapi setelah periode kesembilan kurang begitu mendekati nilai aktualnya. Model ini terlihat secara grafis lebih bagus dari model SMA tetapi masih kurang bagus bila dibanding model WMA. Hasil analisis data masing-masing model ditunjulkan secara grafis diatas. Hasil perbandingan secara grafis ditunjukkan dalam Gambar 5 dibawah ini.

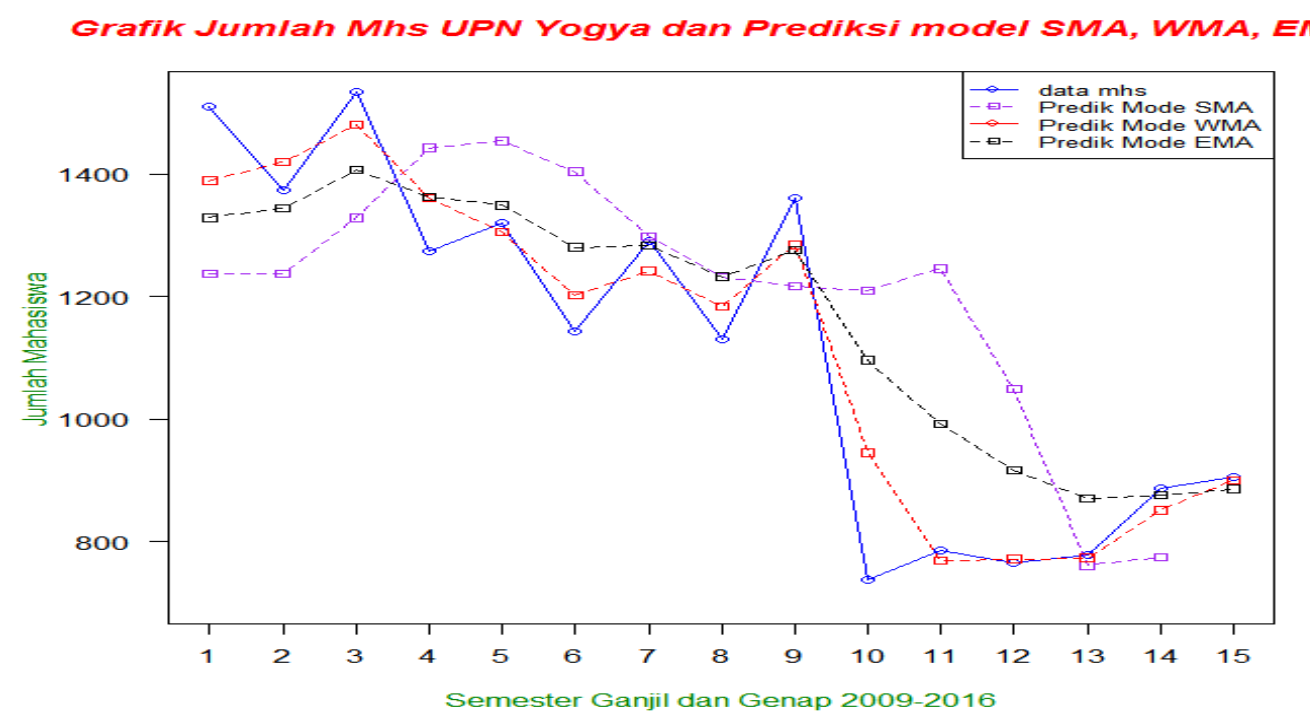

Gambar 5. Perbandingan grafik data aktual, model SMA, model WMA dan model EMA

\subsection{Pembahasan}

Perbandingan keseluruhan model SMA, WMA, dan EMA pada gambar 5 diatas menunjukkan bahwa model WMA lebih dekat ke data aktual jumlah mahasiswa. Tidaklah cukup dan mungkin kita akan menyimpulkan tidak obyektif bila kita membandingkan secara grafis saja bukan

dengan angka, untuk itu akan kita bandingkan secara angka dengan menggunakan akurasi peramalan. Akurasi yang dipakai yaitu mean square error (MSE), mean absolute error (MAE) dan mean absolute percentage error (MAPE). Hasil perhitungannya disajikan dalam Tabel 3 berikut.

Tabel 3. Nilai akurasi (MSE, MAE dan MAPE) untuk model SMA, WMA dan EMA

\begin{tabular}{|c|c|c|c|}
\hline $\begin{array}{c}\text { Akurasi } \\
/ \\
\text { Model }\end{array}$ & MSE & MAE & MAPE \\
\hline SMA & 37086.61 & 142.5714 & 0.1482000 \\
\hline WMA & 5807.963 & 55.88889 & 0.0524132 \\
\hline EMA & 19974.14 & 108.7097 & 0.1132568 \\
\hline
\end{tabular}

Dari Tabel 3 di atas tampak bahwa nilai terkecil untuk MSE adalah pada model WMA sebesar 5807,963 . Nilai terkecil untuk MAE adalah pada model WMA sebesar 55,88889 dan yang 
terkecil untuk MAPE adalah pada WMA sebesar 0,0524132. Dari ketiga nilai akurasi yang dipakai untuk membandingkan ketiga model MSE, WMA dan EMA ternyata pada model WMA nilai akurasinya paling kecil semua, ini berarti bahwa model WMA adalah model terbaik untuk peramalan jumlah mahasiswa jurusan informatika di UPN Yogyakarta. Selanjutnya akan dilakukan peramalan jumlah mahasiswa 4 periode kedapan. Hasil peramalan akan disajikan dalam Gambar 6. berikut ini :

Grafik Jumlah Mhs UPN Yogya dan Prediksi 4 periode kedepan model WMA

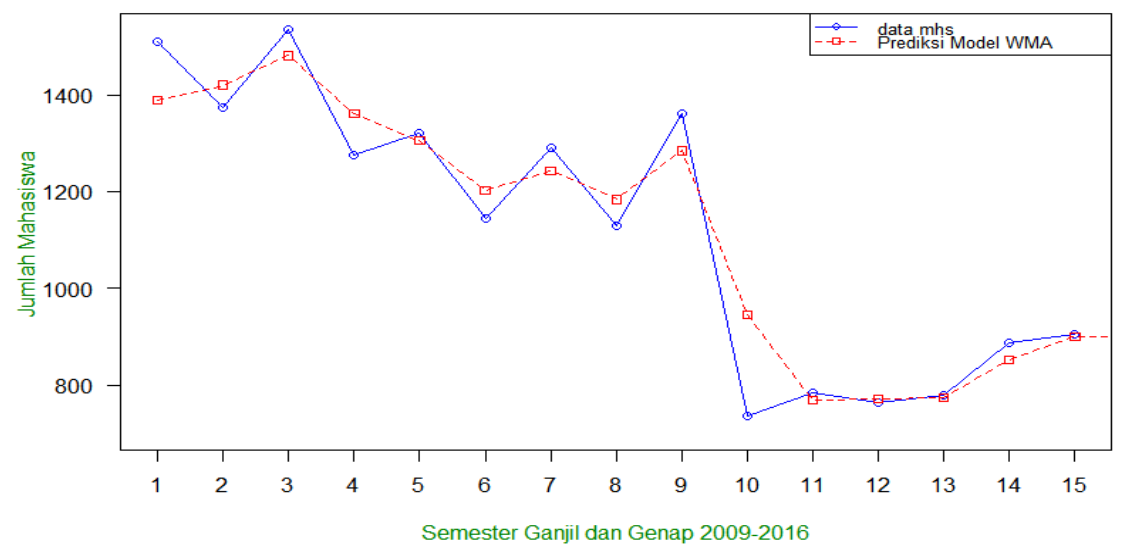

\section{Gambar 6. Plot Nilai aktual dan nilai ramalan model WMA untuk 4 periode kedepan (dengan $\mathbf{R}$, gak bisa keluar 4 periode kedepan)}

Dari gambar 6 dan hasil perhitungan peramalan 4 periode kedepan masing-masing adalah 902; 901,33; 901,56; 901,48

\section{KESIMPULAN}

Dari penelitian ini dapat dibuat kesimpulan sebagai berikut :

1. Model Terbaik yang dapat digunakan untuk meramalkan jumlah mahasiswa yang kuliah di jurusan informatika UPN Yogyakarta adalah model Weighted Moving Average (WMA) dengan nilai akurasi peramalan (MSE, WMA dan EMA) terkecil sebesar masing-masing 5807.963; 55.88889 dan 0.0524132

2. Hasil peramalan jumlah mahasiswa yang kuliah di jurusan informatika UPN Yogyakarta untuk 4 periode kedepan (genap 2017, ganjil 2017, genap 2018 dan ganjil 2018) dari model WMA yaitu : 789; 899; 965 dan 985.

3. Dari kesimpulan point 1 dan 2 dapat digunakan sebagai salah satu acuan dalam pengambilan keputusan dalam proses belajar mengajar di jurusan UPN Yogyakarta.

4. Disarankan untuk penelitian yang akan datang atau prediksi jumlah mahasiswa yang akan datang digunakan pembanding motode lain seperti exponensial moving average dua parameter atau autoregressive moving average.

\section{DAFTAR PUSTAKA}

Asad, M., Wibowo, S. S. and Sophia, E. (2017) 'Peramalan Jumlah Mahasiswa Baru Dengan Model Autoregressive Integrated Moving Average ( Arima )', Jurnal Informatika Merdeka Pasuruan, 2(3), pp. 20-33. 
George Box, J. R. (1994): Time Series Analysis, Forecasting and Control. Englewood Cliffs: Prentice Hall

Hansun, S. (2013) 'A New Approach of Moving Average Method in Time Series Analysis', 2013 Conference on New Media Studies (CoNMedia), pp. 1-4. doi: 10.1109/CoNMedia.2013.6708545.

Hansun, S., Subanar (2017) 'Brown's Weighted Exponential Moving Average Implementation in Forex Forecasting'. TELKOMNIKA, Vol.15, No.3, September 2017, pp. 1425 1432

Lauren, S. (2014) 'Stock Trend Prediction Using Simple Moving Average Supported by News Classification', (1), pp. 135-139.

Makridakis, S. Steven, C Wheelwright. Victor, E Mcgee. (1992). Metode dan Aplikasi Peramalan Jilid 2. Jakarta: Erlangga.

NIST/SEMATECH e-Handbook of Statistical Methods. Forecasting with Single Exponential Smoothing. download on November 17, 2016 from http://www.itl.nist.gov/div898/handbook/pmc/section4/pmc432.htm.

Sundari, S. S., Susanto and Revianti, W. (2015) 'Sistem Peramalan Persediaan Barang Dengan Weight Moving Average Di Toko The Kids 24', pp. 9-10. 